\title{
Side effects of chaperone gene co-expression in recombinant protein production
}

\author{
Mónica Martínez-Alonso ${ }^{1,2,3}$, Elena García-Fruitós ${ }^{1,2,3}$, Neus Ferrer-Miralles ${ }^{1,2,3}$, Ursula Rinas $^{4,5}$, Antonio Villaverde ${ }^{1,2,3^{*}}$
}

\begin{abstract}
Insufficient availability of molecular chaperones is observed as a major bottleneck for proper protein folding in recombinant protein production. Therefore, co-production of selected sets of cell chaperones along with foreign polypeptides is a common approach to increase the yield of properly folded, recombinant proteins in bacterial cell factories. However, unbalanced amounts of folding modulators handling folding-reluctant protein species might instead trigger undesired proteolytic activities, detrimental regarding recombinant protein stability, quality and yield. This minireview summarizes the most recent observations of chaperone-linked negative side effects, mostly focusing on DnaK and GroEL sets, when using these proteins as folding assistant agents. These events are discussed in the context of the complexity of the cell quality network and the consequent intricacy of the physiological responses triggered by protein misfolding.
\end{abstract}

\section{Review}

Poor product quality is a common event in the biological synthesis of target proteins and a major cause for recombinant enzymes and pharmaceuticals to be excluded from the market [1]. Recombinant protein misfolding and the triggering of the consequent cell responses are both general events among microbial cell factories [2]. Although what protein quality means might be highly controversial [3-5], it is in general assumed that the soluble protein version, despite the potential occurrence of soluble aggregates $[4,6-10]$ and the presence of functional protein species in protein aggregates [4,11-15], is the most desirable form of the final product of a protein production process. Traditionally, gaining solubility has been approached by tuningdown the production rate (e.g. by decreasing temperature), reducing recombinant gene dosage or the strength of the promoter, or supplying additional amounts of host chaperones, as they are seen as limiting during the overproduction of misfolding-prone protein species $[16,17]$.

Under the high substrate load context of recombinant cells, chaperones, main players in the quality control system, might be over-titrated and therefore their

\footnotetext{
* Correspondence: avillaverde@servet.uab.es

'Institute for Biotechnology and Biomedicine, Universitat Autònoma de Barcelona, Bellaterra, 08193 Barcelona, Spain

Full list of author information is available at the end of the article
}

protein targets excluded from folding pathways leading to the native conformation, accumulating as refractile particles called inclusion bodies (IBs) [13,18]. Therefore, several individual chaperones or chaperone sets have been selected for overproduction along with the target recombinant protein. In Escherichia coli (E. coli), most of these approaches have involved the two main cytosolic chaperones, namely DnaK and GroEL, as well as some of their co-chaperones [6,19]. However, the fine examination of physiological responses to protein production in bacteria and other microorganisms [2,10,20-22], has revealed that chaperone co-production, as a quality-addressed strategy, might eventually show undesirable side effects regarding protein yield and quality (Table 1). Here we summarize the main indications pointing out the chaperone side-effects, mainly focusing on DnaK, GroEL and their cooperating folding modulators.

\section{DnaK}

DnaK, homolog of the eukaryotic Hsp70, is the major cytosolic chaperone in E. coli, and plays an important role in the control of conformational quality. In fact, DnaK is involved in different activities such as prevention of aggregation, folding and refolding of misfolded species and protein disaggregation [23-27]. For this reason, DnaK has often been used in co-production approaches, either together with its co-chaperone DnaJ 
Table 1 Main undesired side effects observed during chaperone co-production on the quality and yield of recombinant proteins produced in $E$. coli, as exemplified by representative studies

\begin{tabular}{|c|c|c|c|}
\hline Chaperone/Chaperone set & Recombinant protein & Effects on protein production & References \\
\hline DnaKJE & Horseradish peroxidase & Growth inhibition & {$[31]$} \\
\hline DnaKJ & Aggregation-prone GFP & $\begin{array}{l}\text { Proteolyis, reduced yield and lower conformational } \\
\text { quality }\end{array}$ & {$[20,21]$} \\
\hline DnaKJE and/or Trigger Factor & Guinea pig liver transglutaminase & Reduced specific activity & {$[74]$} \\
\hline DnaKJE, ClpB and GroELS & Basic fibroblast growth factor & Reduced yield & {$[22]$} \\
\hline $\begin{array}{l}\text { DnaKJE-GroELS-ClpB and Trigger } \\
\text { Factor }\end{array}$ & $\begin{array}{l}\text { Human protein kinase catalytic } \\
\text { domains }\end{array}$ & Increased soluble aggregate formation & {$[43]$} \\
\hline GroELS & Basic fibroblast growth factor & Proteolysis, reduced yield & {$[22]$} \\
\hline Trigger Factor and GroELS & N-acyl-D-amino acid amidohydrolases & Reduced specific activity & {$[75]$} \\
\hline GroELS & Fab Antibody Fragment & Reduced yield & {$[46]$} \\
\hline GroELS & scFv antibody fragment & Reduced solubility & {$[76]$} \\
\hline GroELS & Cyclodextrin glycosyltransferase & Reduced specific activity & [32] \\
\hline
\end{tabular}

$[20,28]$ or both with DnaJ and their nucleotide exchange factor GrpE [6,29-36] to minimize aggregation and to enhance solubility of the recombinant protein [37-40]. Co-chaperones have been observed as necessary because over-expression of $d n a K$ gene alone is toxic for the cell, leading to growth inhibition and abnormal septation [41]. Although this approach has proven to be useful in many cases $[34,42]$, this set of folding modulators has not been consistently successful to enhance solubility of target recombinant proteins [43-45] and solubility has been often enhanced at expenses of protein yield $[29,32,34]$. This fact has been attributed both to cell growth inhibition $[31,35,46]$ and to the proteolysis of the recombinant protein $[20,31,35]$. Besides its mentioned activities, recent publications describe that DnaK is also involved in the degradation of aggregation-prone but functional (or suitable to be activated) polypeptides by targeting them to proteases such as Lon and ClpP [47-49]. In fact, absence of a functional DnaK results in increased proteolytic resistance of a target protein, the half-life of which is increased up to three-fold in these conditions [21]. Hence, this dual role of the chaperone, which acts both as a folding modulator and as proteolytic enhancer, contributes to explain the divergence of results obtained upon its co-production. Although recombinant protein solubility can be improved by high levels of DnaK and its co-chaperones, protein quality might be compromised since an important part of this effect is obtained by increasing soluble aggregate species $[9,21]$ with variable specific activity. In addition, yield of recombinant protein decreases due to the proteolysis stimulation carried out by DnaK [22]. The occurrence of such a DnaK-mediated side effect proves that strategies developed to optimize recombinant protein production processes have to be redefined, considering that solubility and conformational quality are independently controlled.
Moreover, because DnaK is also a negative regulator of the heat shock response [50], an enhanced concentration of DnaK above physiological levels can result in down-regulation of other heat shock proteins. Actually, decreased levels of GroEL chaperone have been reported in DnaK-overproducing cells $[28,51]$. Thus, taking into account that selection of the appropriate set of folding modulators is still a trial and error process, this scenario may then result in a more pronounced folding impairment for proteins that not only require interaction with DnaK but also with the GroEL system.

\section{GroEL(S)}

The GroELS heat shock chaperone team is of vital importance for E. coli with GroEL being an essential protein for growth at all temperatures [52]. Co-production of this chaperone team has been widely applied to improve the solubility of proteins which tend to form IBs, in many cases with remarkable success $[37,38,53,54]$. However, also failures of GroELS to improve solubility have been reported, mostly the impact of GroELS was neutral, namely without increasing the amount of properly folded protein $[55,56]$ or decreasing the amount of IB-deposited target protein [57]. In particular, failures of GroELS co-production for improved target protein solubility have been observed when aiming for production of large proteins [55]. This is a comprehensible finding as large proteins can not enter the cavity formed by the GroEL chaperone [58] thus leading to a preference of GroEL for substrate proteins in the molecular mass range of $10 / 20-55 / 60 \mathrm{kDa}$ [59-61].

In addition, past studies also indicated that GroEL is involved in promoting proteolytic degradation through target protein binding [62-65]. In fact, the natural role of GroEL not only includes chaperoning functions but also encompasses a vital role in fostering proteolytic 
degradation. For example, GroEL plays a central role in promoting proteolytic degradation of a regulatory protein to reduce potentially detrimental effects of nontuned gene expression [66]. In addition, GroELS is also involved in "protein trash removal", namely fostering proteolytic degradation of endogenous protein aggregates generated during heat shock [67].

A detailed study on the involvement of GroELS in target protein degradation was carried out during temperature-induced production of basic fibroblast growth factor [22]. Temperature-induced production leads to the formation of soluble growth factor and growth factor deposited in the form of IBs [68]. Protein purified from the soluble cell fraction of temperature-induced cells is biologically active as determined by mitogenic activity measurements [69]. Co-production of GroELS does not prevent IB formation but leads to complete IB dissolution followed by proteolytic degradation of basic fibroblast growth factor [22]. In this case, IB dissolution followed by proteolytic degradation of the target protein was more efficient with GroELS than with the DnaKJ/ GrpE system.

\section{Solving chaperone-promoted proteolysis}

Despite the mentioned reports indicating DnaK-induced proteolysis upon recombinant protein production, it is difficult to find in the literature any attempt to solve this problem. Even in E. coli genetic backgrounds knockout for the main cytosolic protease gene (Lon), proteolytic activity is still a hurdle to recombinant protein production probably by induction of other proteolytic systems [70]. However, in a recent study [71] we addressed this issue by re-hosting DnaK and its co-chaperone DnaJ into a system lacking orthologs of the

\section{To increase recombinant protein quality}

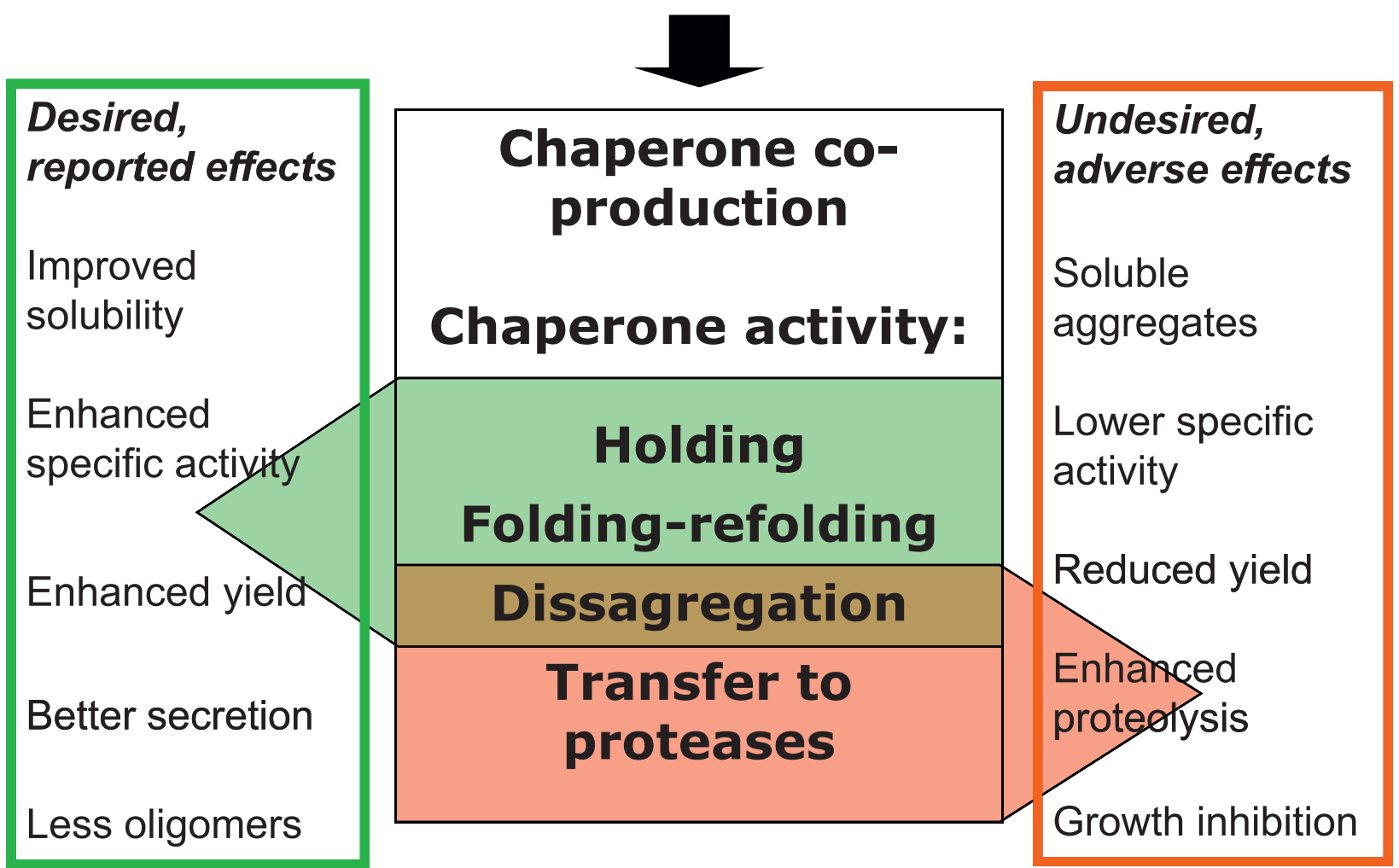

Figure 1 Aimed to increase recombinant quality and solubility, co-production of individual chaperones or chaperone sets has been a common strategy since the role of these proteins in quality control has been solved, mainly involving protein holding to prevent aggregation, folding or refolding activities and disaggregation from inclusion bodies. Many studies report on the positive effects of chaperone gene co-expression, regarding solubility, yield, secretion ability and specific activity (green box). However, it is also true that this strategy has been largely controversial and the eventual success seen as highly product- and/or process-dependent. Also, more recent studies reveal that an excess of certain chaperones has negative effects on protein yield and other parameters related to protein quality (red box), mainly due to the role of chaperones in promoting proteolysis of folding reluctant proteins. This promotion of proteolysis seems to be mechanistically linked to the disaggregation activities ruled by DnaK $[21,77]$. 
bacterial proteases responsible for the protein degradation mediated by DnaK. The goal of such approach was to uncouple the valuable folding activity of DnaK from its other activities linked to proteolysis. Because DnaK has been highly conserved in evolution (DnaK homologs can be found in all kingdoms of life) the reasoning was that its folding activity could be conserved in other organisms, but not so the associated proteolytic activity because it is dependent on the bacterial proteases Lon and ClpP. Insect cells were chosen as the host for the $E$. coli DnaKJ chaperone pair, which was introduced in the production system upon infection of the cells with recombinant baculovirus vectors carrying the corresponding genes. In this eukaryotic system, chaperone gene co-expression resulted in enhanced yield and biological activity of a reporter protein, which also showed increased stability in presence of the bacterial chaperones, indicative of absence of DnaK-mediated proteolysis. This was in marked contrast to what had previously been described in $E$. coli for the production of the same protein and chaperone combination [21]. The same study also showed positive effects of the set of bacterial folding modulators on the production of three other recombinant proteins in the insect cell-baculovirus system, namely VP1 and VP2 from the capsid of Foot-andMouth Disease Virus, and human $\alpha$-galactosidase. A later, related study [72] extended this approach to an in vivo model by using the recombinant baculoviruses encoding the bacterial chaperones to infect insect larvae, a system of use as a biofactory but where yields are usually reduced due to protein aggregation. In this system, absence of DnaK-induced proteolysis was also evident, and co-production of the bacterial chaperones boosted protein solubility by almost 100\%. Taken together, these studies not only show how the effective discrimination of activities has been a suitable strategy to exclude the undesirable effects of the DnaKJ chaperone pair, but also prove that bacterial folding modulators are functional in other recombinant systems.

\section{Conclusions}

Despite their proven success as folding modulators in protein production processes, bacterial chaperones (mainly DnaK and GroEL and associated cofactors) also show undesired side effects related to their activities in promoting proteolysis of target proteins (Figure 1). This fact might account, at least partially, for the inconsistent results reported upon the use of these chaperones in years of exploitation of microbial cell factories for protein production. Because of the lack of coincidence and the divergent control of protein solubility and quality observed in bacteria [3,21], chaperone co-production might have enhanced solubility as a consequence of an undesired reduction of recombinant protein yield.
Probably, most failures of chaperone gene co-expression on target protein solubility have not been reported in the scientific literature (including our own observations) and, in some cases, a supposed positive effect of chaperone co-production might just reflect the presence of soluble aggregates but not of functional protein [43]. Moreover, over-production of chaperones as over-production of any other protein can contribute to the metabolic burden thereby leading to growth rate reduction as well as decreased final biomass yields [73]. As a first example, re-hosting of bacterial chaperones has proven to be a way to disconnect folding assistance and proteolysis. However, further studies are still needed to explore other alternative ways to systematically minimize chaperone side effects in protein production, keeping their desired activities on folding-reluctant recombinant proteins.

\section{Acknowledgements}

The authors appreciate the financial support through MEC (BIO2007-61194). We also appreciate the support from The Biomedical Research Networking Center in Bioengineering, Biomaterials and Nanomedicine (CIBER-BBN, Spain), an initiative funded by the VI National R\&D\&i Plan 2008-2011, Iniciativa Ingenio 2010, Consolider Program, CIBER Actions and financed by the Instituto de Salud Carlos III with assistance from the European Regional Development Fund. Antonio Villaverde has been granted with an ICREA ACADEMIA award (from ICREA, Catalonia, Spain).

\section{Author details}

${ }^{1}$ Institute for Biotechnology and Biomedicine, Universitat Autònoma de Barcelona, Bellaterra, 08193 Barcelona, Spain. ${ }^{2}$ Department of Genetics and Microbiology, Universitat Autònoma de Barcelona,08193, Bellaterra Barcelona, Spain. ${ }^{3}$ CIBER de Bioingeniería, Biomateriales y Nanomedicina (CIBER-BBN), Bellaterra, 08193 Barcelona, Spain. ${ }^{4}$ Helmholtz Centre for Infection Research, Inhoffenstr. 7, 38124 Braunschweig, Germany. ${ }^{5}$ Leibniz University Hannover, Life Science - Technical Chemistry, Callinstr. 5, 30167 Hannover, Germany.

\section{Authors' contributions}

All authors have contributed to this review from their complementing areas of expertise and have read and approved the final manuscript.

\section{Competing interests}

The authors declare that they have no competing interests.

Received: 15 July 2010 Accepted: 2 September 2010 Published: 2 September 2010

\section{References}

1. Ferrer-Miralles N, Domingo-Espin J, Corchero JL, Vazquez E, Villaverde A: Microbial factories for recombinant pharmaceuticals. Microb Cell Fact 2009, 8:17.

2. Gasser B, Saloheimo M, Rinas U, Dragosits M, Rodriguez-Carmona E, Baumann $\mathrm{K}$, et al: Protein folding and conformational stress in microbial cells producing recombinant proteins: a host comparative overview. Microb Cell Fact 2008, 7:11.

3. Gonzalez-Montalban N, Garcia-Fruitos E, Villaverde A: Recombinant protein solubility-does more mean better? Nat Biotechnol 2007, 25:718-720.

4. Martinez-Alonso M, Gonzalez-Montalban N, Garcia-Fruitos E, Villaverde A: Learning about protein solubility from bacterial inclusion bodies. Microb Cell Fact 2009, 8:4.

5. de Marco A: Minimal information: an urgent need to assess the functional reliability of recombinant proteins used in biological experiments. Microb Cell Fact 2008, 7:20.

6. de Marco A, De Marco V: Bacteria co-transformed with recombinant proteins and chaperones cloned in independent plasmids are suitable for expression tuning. J Biotechnol 2004, 109:45-52. 
7. Toledo-Rubio V, Vazquez E, Platas G, Domingo-Espin J, Unzueta U,

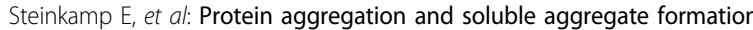
screened by a fast microdialysis assay. J Biomol Screen 2010, 15:453-457.

8. de Marco A, Schroedel A: Characterization of the aggregates formed during recombinant protein expression in bacteria. BMC Biochem 2005, 6:10.

9. Martinez-Alonso M, Gonzalez-Montalban N, Garcia-Fruitos E, Villaverde A: The functional quality of soluble recombinant polypeptides produced in Escherichia coli is defined by a wide conformational spectrum. Appl Environ Microbiol 2008, 101:1353-1358.

10. Martinez-Alonso M, Garcia-Fruitos E, Villaverde A: Yield, solubility and conformational quality of soluble proteins are not simultaneously favored in recombinant Escherichia coli. Biotechnol Bioeng 2008, 101:1353-1358.

11. Jevsevar S, Gaberc-Porekar V, Fonda I, Podobnik B, Grdadolnik J, Menart V: Production of nonclassical inclusion bodies from which correctly folded protein can be extracted. Biotechnol Prog 2005, 21:632-639.

12. Peternel S, Grdadolnik J, Gaberc-Porekar V, Komel R: Engineering inclusion bodies for non denaturing extraction of functional proteins. Microb Cell Fact 2008, 7:34.

13. Garcia-Fruitos E, Villaverde A: Friendly production of bacterial inclusion bodies. Korean J Chem Eng 2010, 27:385-389.

14. Garcia-Fruitos E, Aris A, Villaverde A: Localization of functional polypeptides in bacterial inclusion bodies. Appl Environ Microbiol 2007, 73:289-294.

15. Garcia-Fruitos E, Gonzalez-Montalban N, Morell M, Vera A, Ferraz RM, Aris A, et al: Aggregation as bacterial inclusion bodies does not imply inactivation of enzymes and fluorescent proteins. Microb Cell Fact 2005, 4:27.

16. Sorensen HP, Mortensen KK: Soluble expression of recombinant proteins in the cytoplasm of Escherichia coli. Microb Cell Fact 2005, 4:1.

17. Sorensen HP, Mortensen KK: Advanced genetic strategies for recombinant protein expression in Escherichia coli. J Biotechnol 2005, 115:113-128.

18. Villaverde A, Carrio MM: Protein aggregation in recombinant bacteria: biological role of inclusion bodies. Biotechnol Lett 2003, 25:1385-1395.

19. de Marco A: Protocol for preparing proteins with improved solubility by co-expressing with molecular chaperones in Escherichia coli. Nat Protoc 2007, 2:2632-2639.

20. Martinez-Alonso M, Vera A, Villaverde A: Role of the chaperone DnaK in protein solubility and conformational quality in inclusion body-forming Escherichia coli cells. FEMS Microbiol Lett 2007, 273:187-195.

21. Garcia-Fruitos E, Martinez-Alonso M, Gonzalez-Montalban N, Valli M, Mattanovich D, Villaverde A: Divergent Genetic Control of Protein Solubility and Conformational Quality in Escherichia coli. J Mol Biol 2007 374:195-205.

22. Rinas U, Hoffmann F, Betiku E, Estape D, Marten S: Inclusion body anatomy and functioning of chaperone-mediated in vivo inclusion body disassembly during high-level recombinant protein production in Escherichia coli. J Biotechnol 2007, 127:244-257.

23. Gragerov A, Nudler E, Komissarova N, Gaitanaris GA, Gottesman ME, Nikiforov V: Cooperation of GroEL/GroES and DnaK/DnaJ heat shock proteins in preventing protein misfolding in Escherichia coli. Proc Nat Acad Sci USA 1992, 89:10341-10344.

24. Langer T, Lu C, Echols H, Flanagan J, Hayer MK, Hartl FU: Successive action of DnaK, DnaJ and GroEL along the pathway of chaperone-mediated protein folding. Nature 1992, 356:683-689.

25. Mogk A, Deuerling E, Vorderwulbecke S, Vierling E, Bukau B: Small heat shock proteins, ClpB and the DnaK system form a functional triade in reversing protein aggregation. Mol Microbiol 2003, 50:585-595.

26. Schlieker C, Tews I, Bukau B, Mogk A: Solubilization of aggregated proteins by $\mathrm{ClpB} / \mathrm{DnaK}$ relies on the continuous extraction of unfolded polypeptides. FEBS Lett 2004, 578:351-356.

27. Thomas JG, Baneyx F: Protein folding in the cytoplasm of Escherichia coli: requirements for the DnaK-DnaJ-GrpE and GroEL-GroES molecular chaperone machines. Mol Microbiol 1996, 21:1185-1196.

28. Thomas JG, Baneyx F: Protein misfolding and inclusion body formation in recombinant Escherichia coli cells overexpressing Heat-shock proteins. J Biol Chem 1996, 271:11141-11147.

29. Choi GH, Lee DH, Min WK, Cho YJ, Kweon DH, Son DH, et al: Cloning, expression, and characterization of single-chain variable fragment antibody against mycotoxin deoxynivalenol in recombinant Escherichia coli. Protein Expr Purif 2004, 35:84-92.

30. Lee DH, Kim MD, Lee WH, Kweon DH, Seo JH: Consortium of foldcatalyzing proteins increases soluble expression of cyclohexanone monooxygenase in recombinant Escherichia coli. Appl Microbiol Biotechnol 2003.

31. Kondo A, Kohda J, Endo Y, Shiromizu T, Kurokawa Y, Nishihara K, et al: Improvement of productivity of active horseradish peroxidase in Escherichia coli by coexpression of Dsb proteins. J Biosci Bioeng 2000, 90:600-606.

32. Kim SG, Kweon DH, Lee DH, Park YC, Seo JH: Coexpression of folding accessory proteins for production of active cyclodextrin glycosyltransferase of Bacillus macerans in recombinant Escherichia coli. Protein Expr Purif 2005, 41:426-432.

33. Kirschner A, Altenbuchner J, Bornscheuer UT: Cloning, expression, and characterization of a Baeyer-Villiger monooxygenase from Pseudomonas fluorescens DSM 50106 in E. coli. Appl Microbiol Biotechnol 2007 73:1065-1072.

34. de Marco A, Deuerling E, Mogk A, Tomoyasu T, Bukau B: Chaperone-based procedure to increase yields of soluble recombinant proteins produced in E. coli. BMC Biotechnol 2007, 7:32.

35. Nishihara K, Kanemori M, Yanagi H, Yura T: Overexpression of trigger factor prevents aggregation of recombinant proteins in Escherichia coli. Appl Environ Microbiol 2000, 66:884-889.

36. Nishihara K, Kanemori M, Kitagawa M, Yanagi H, Yura T: Chaperone coexpression plasmids: differential and synergistic roles of DnaK-DnaJGrpE and GroEL-GroES in assisting folding of an allergen of Japanese cedar pollen, Cryj2, in Escherichia coli. Appl Environ Microbiol 1998, 64:1694-1699.

37. Baneyx F, Palumbo JL: Improving heterologous protein folding via molecular chaperone and foldase co-expression. Methods Mol Biol 2003, 205:171-197.

38. Hoffmann F, Rinas U: Roles of heat-shock chaperones in the production of recombinant proteins in Escherichia coli. Adv Biochem Eng Biotechnol 2004, 89:143-161.

39. Schlieker C, Bukau B, Mogk A: Prevention and reversion of protein aggregation by molecular chaperones in the E. coli cytosol: implications for their applicability in biotechnology. J Biotechnol 2002, 96:13-21.

40. Thomas JG, Ayling A, Baneyx F: Molecular chaperones, folding catalysts, and the recovery of active recombinant proteins from $E$. coli. To fold or to refold. Appl Biochem Biotechnol 1997, 66:197-238.

41. Blum P, Ory J, Bauernfeind J, Krska J: Physiological consequences of DnaK and DnaJ overproduction in Escherichia coli. J Bacteriol 1992, 174:7436-7444

42. Skretas G, Carroll S, DeFrees S, Schwartz MF, Johnson KF, Georgiou G: Expression of active human sialyltransferase ST6GalNAcl in Escherichia coli. Microb Cell Fact 2009, 8:50

43. Haacke A, Fendrich G, Ramage P, Geiser M: Chaperone over-expression in Escherichia coli: Apparent increased yields of soluble recombinant protein kinases are due mainly to soluble aggregates. Protein Expr Purif 2008.

44. Wall JG, Pluckthun A: Effects of overexpressing folding modulators on the in vivo folding of heterologous proteins in Escherichia coli. Curr Opin Biotechnol 1995, 6:507-516.

45. Thomas JG, Baneyx F: Divergent effects of chaperone overexpression and ethanol supplementation on inclusion body formation in recombinant Escherichia coli. Protein Expr Purif 1997, 11:289-296.

46. Levy R, Weiss R, Chen G, Iverson BL, Georgiou G: Production of correctly folded Fab antibody fragment in the cytoplasm of Escherichia coli trxB gor mutants via the coexpression of molecular chaperones. Protein Expr Purif 2001, 23:338-347.

47. Jubete Y, Maurizi MR, Gottesman S: Role of the heat shock protein DnaJ in the lon-dependent degradation of naturally unstable proteins. J Biol Chem 1996, 271:30798-30803.

48. Sherman MY, Goldberg AL: Involvement of the chaperonin dnaK in the rapid degradation of a mutant protein in Escherichia coli. EMBO J 1992, 11:71-77.

49. Straus D, Walter W, Gross CA: DnaK, DnaJ, and GrpE heat shock proteins negatively regulate heat shock gene expression by controlling the synthesis and stability of sigma 32. Genes Dev 1990, 4:2202-2209. 
50. Rodriguez F, Arsene-Ploetze F, Rist W, Rudiger S, Schneider-Mergener J, Mayer MP, et al: Molecular basis for regulation of the heat shock transcription factor sigma32 by the DnaK and DnaJ chaperones. Mol Cell 2008, 32:347-358.

51. Petersson L, Carrio MM, Vera A, Villaverde A: The impact of dnaKJ overexpression on recombinant protein solubility results from antagonistic effects on the control of protein quality. Biotechnol Lett 2004, 26:595-601.

52. Fayet O, Ziegelhofer T, Georgopoulos C: The groES and groEL heat shock gene products of Escherichia coli are essential for bacterial growth at all temperatures. J Bacteriol 1989, 171:1379-1385.

53. Kolaj O, Spada S, Robin S, Wall JG: Use of folding modulators to improve heterologous protein production in Escherichia coli. Microb Cell Fact 2009, 8:9.

54. Georgiou G, Valax P: Expression of correctly folded proteins in Escherichia coli. Curr Opin Biotechnol 1996, 7:190-197.

55. Han KG, Lee SS, Kang C: Soluble expression of cloned phage K11 RNA polymerase gene in Escherichia coli at a low temperature. Protein Expr Purif 1999, 16:103-108.

56. Moon HJ, Jeya M, Yu IS, Ji JH, Oh DK, Lee JK: Chaperone-aided expression of LipA and LpIA followed by the increase in $\alpha$-lipoic acid production. Appl Microbiol Biotechnol 2009, 83:329-337.

57. Sun AL, Hua ZC, Yao J, Yang YH, Yin DQ: Fusion expression of human prourokinase with E. coli thioredoxin. Biochem Mol Biol Int 1998, 46:479-486.

58. Sakikawa C, Taguchi H, Makino Y, Yoshida M: On the maximum size of proteins to stay and fold in the cavity of GroEL underneath GroES. J Biol Chem 1999, 274:21251-21256.

59. Ewalt KL, Hendrick JP, Houry WA, Hartl FU: In vivo observation of polypeptide flux through the bacterial chaperonin system. Cell 1997, 90:491-500.

60. Houry WA, Frishman D, Eckerskorn C, Lottspeich F, Hartl FU: Identification of in vivo substrates of the chaperonin GroEL. Nature 1999, 402:147-154.

61. Kerner MJ, Naylor DJ, Ishihama Y, Maier T, Chang HC, Stines AP, et al: Proteome-wide analysis of chaperonin-dependent protein folding in Escherichia coli. Cell 2005, 122:209-220.

62. Kandror O, Busconi L, Sherman M, Goldberg AL: Rapid degradation of an abnormal protein in Escherichia coli involves the chaperones GroEL and GroES. J Biol Chem 1994, 269:23575-23582.

63. Kandror O, Sherman M, Goldberg A: Rapid degradation of an abnormal protein in Escherichia coli proceeds through repeated cycles of association with GroEL. J Biol Chem 1999, 274:37743-37749.

64. Kandror O, Sherman M, Rhode M, Goldberg AL: Trigger factor is involved in GroEL-dependent protein degradation in Escherichia coli and promotes binding of GroEL to unfolded proteins. EMBO J 1995, 14:6021-6027.

65. Kandror O, Sherman M, Moerschell R, Goldberg AL: Trigger factor associates with GroEL in vivo and promotes its binding to certain polypeptides. J Biol Chem 1997, 272:1730-1734.

66. Zahrl D, Wagner A, Tscherner M, Koraimann G: GroEL plays a central role in stress-induced negative regulation of bacterial conjugation by promoting proteolytic degradation of the activator protein TraJ. J Bacteriol 2007, 189:5885-5894

67. Kedzierska S, Staniszewska M, Wegrzyn A, Taylor A: The role of DnaK/DnaJ and GroEL/GroES systems in the removal of endogenous proteins aggregated by heat-shock from Escherichia coli cells. FEBS Lett 1999, 446:331-337

68. Seeger A, Schneppe B, McCarthy JEG, Deckwer WD, Rinas U: Comparison of temperature- and isopropyl- $\beta$-D-thiogalacto-pyranoside-induced synthesis of basic fibroblast growth factor in high-cell-density cultures of recombinant Escherichia coli. Enzyme Microb Technol 1995, 17:947-953.

69. Seeger A, Rinas U: Two-step chromatographic procedure for purification of basic fibroblast growth factor from recombinant Escherichia coli and characterization of the equilibrium parameters of adsorption. $J$ Chromatogr A 1996, 746:17-24.

70. Straus DB, Walter WA, Gross CA: Escherichia coli heat shock gene mutants are defective in proteolysis. Genes Dev 1988, 2:1851-1858.

71. Martinez-Alonso M, Toledo-Rubio V, Noad R, Unzueta U, Ferrer-Miralles N, Roy $\mathrm{P}$, et al: Re-hosting bacterial chaperones for high-quality protein production. Appl Environ Microbiol 2009

72. Martinez-Alonso M, Gomez-Sebastian S, Escribano JM, Saiz JC, FerrerMiralles N, Villaverde A: DnaK/DnaJ-assisted recombinant protein production in Trichoplusia ni larvae. Appl Microbiol Biotechnol 2010, 86:633-639.

73. Berges $H$, Joseph-Liauzun $E$, Fayet $O$ : Combined effects of the signal sequence and the major chaperone proteins on the export of human cytokines in Escherichia coli. Appl Environ Microbiol 1996, 62:55-60.

74. Ikura K, Kokubu T, Natsuka S, Ichikawa A, Adachi M, Nishihara K, et al: Cooverexpression of folding modulators improves the solubility of the recombinant guinea pig liver transglutaminase expressed in Escherichia coli. Prep Biochem Biotechnol 2002, 32:189-205.

75. Yoshimune K, Ninomiya Y, Wakayama M, Moriguchi M: Molecular chaperones facilitate the soluble expression of $\mathrm{N}$-acyl-D-amino acid amidohydrolases in Escherichia coli. J Ind Microbiol Biotechnol 2004, 31:421-426.

76. Hu X, O'Hara L, White S, Magner E, Kane M, Wall JG: Optimisation of production of a domoic acid-binding $\mathrm{SCFv}$ antibody fragment in Escherichia coli using molecular chaperones and functional immobilisation on a mesoporous silicate support. Protein Expr Purif 2007 52:194-201.

77. Carrio MM, Villaverde A: Localization of chaperones DnaK and GroEL in bacterial inclusion bodies. J Bacteriol 2005, 187:3599-3601.

doi:10.1186/1475-2859-9-64

Cite this article as: Martínez-Alonso et al:: Side effects of chaperone gene co-expression in recombinant protein production. Microbial Cell Factories 2010 9:64.

\section{Submit your next manuscript to BioMed Central and take full advantage of:}

- Convenient online submission

- Thorough peer review

- No space constraints or color figure charges

- Immediate publication on acceptance

- Inclusion in PubMed, CAS, Scopus and Google Scholar

- Research which is freely available for redistribution

Submit your manuscript at www.biomedcentral.com/submit
C Biomed Central 